\title{
Effect of PGI-2 on uterine activity in vivo in non-pregnant ovariectomized goats (Capra hircus)
}

\author{
R. G. Cooke and A. M. Homeida* \\ University of Liverpool Veterinary Field Station, Leahurst, Chester High Road, Neston, South \\ Wirral, Cheshire L64 7TE, UK; and ${ }^{*}$ Faculty of Veterinary Science, University of Khartoum, \\ Khartoum, Sudan
}

\begin{abstract}
Summary. Jugular administration of $200 \mu \mathrm{g}$ PGI-2 salt significantly reduced spontaneous uterine activity in ovariectomized, oestrogen-primed goats; the effect was acute and persisted for about $3 \mathrm{~h}$. Peripheral plasma concentrations of 6-keto-PGF-1 $\alpha$, the stable metabolite of PGI-2, decreased to $50 \%$ of initial values after $30 \mathrm{~min}$; but at the start of uterine recovery were in excess of $2 \mathrm{ng} . \mathrm{ml}^{-1}$. Uterine reactivity to both oxytocin and PGF-2 $\alpha$ after PGI-2 administration was unaffected.
\end{abstract}

Keywords: prostacyclin; uterus; motility; goat; PGF-2a; oxytoxin

\section{Introduction}

Prostaglandins (PG) of the $\mathrm{E}$ and $\mathrm{F}$ series are generally considered to be the key prostanoids involved in the modulation of uterine activity. However, a role for prostacyclin (PGI-2), a potent vasodilator and inhibitor of platelet aggregation (Moncada et al., 1976), has to be defined. PGI-2 is present in the myometrium and endometrium of non-pregnant and pregnant animals including rats, guinea-pigs, sheep (Jones et al., 1977; Williams et al., 1978), goats (Cooke \& Homeida, 1987) and women (Omini et al., 1979). In-vitro experiments have produced conflicting results: PGI-2 may either inhibit (Omini et al., 1979) or stimulate and then inhibit the pregnant human myometrium (Wikland et al., 1983); myometrial activity in the rat, however, is stimulated (Williams et al., 1979). Lye \& Challis (1982) showed that PGI-2 inhibited both the electrical and mechanical activity of the non-pregnant sheep uterus in vivo, but responsiveness to PGF-2 $\alpha$ and oxytocin were unaffected.

The aims of this study were to examine in ovariectomized goats the effect of PGI- 2 on spontaneous uterine activity, and also the effects of PGI- 2 on uterine reactivity to both PGF-2 $\alpha$ and oxytocin.

\section{Materials and Methods}

Animals and treatments. Four mature female goats of mixed breeding but similar age (3-4 years) and weight $(40-45 \mathrm{~kg})$ were used. The animals, anaesthetized with sodium thiopentone intravenously and maintained with fluothane and oxygen, were ovariectomized through a left-flank incision. A soft polyethylene, air-filled balloon $(27 \times 5 \mathrm{~mm}$; Portex Ltd, Hyde, Kent, UK) attached to a more rigid 40-cm length of cannula was inserted into the uterus via a small incision in the uterine wall; intrauterine pressure was monitored by a Bell and Howell pressure transducer and recorded on a Devices MX-2 machine. Details of the techniques have been described previously (Jones \& Knifton, 1975). Following a post-surgical recovery period of 10 days all 4 animals were treated daily with $60 \mu g$ oestradiol benzoate (Intervet, Cambridge, UK) intramuscularly (i.m.) for 7 days.

On the 6th day of oestradiol administration $200 \mu \mathrm{g}$ PGI-2 sodium salt (Upjohn Co., Kalamazoo, MI, USA) in $1 \mathrm{ml}$ sterile saline $(0.9 \% \mathrm{w} / \mathrm{v} \mathrm{NaCl})$ were injected into the jugular vein of each goat using 23 -gauge needles. Uterine activity was recorded for $30 \mathrm{~min}$ before and for $2.5 \mathrm{~h}$ after PGI-2 administration. Jugular venous blood was collected by direct venepuncture into chilled heparinized tubes immediately before treatment and then at 10 -min intervals for $120 \mathrm{~min}$. Plasma was separated, snap-frozen in $\mathrm{CO}_{2}$-acetone and stored at $-20^{\circ} \mathrm{C}$; samples were later analysed for the 


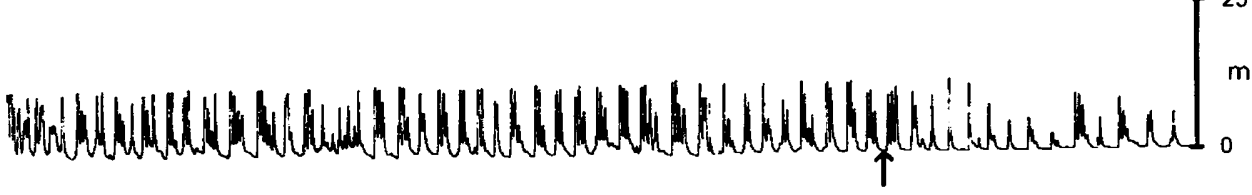 \\ $200 \mu \mathrm{g}$ PGI-2}

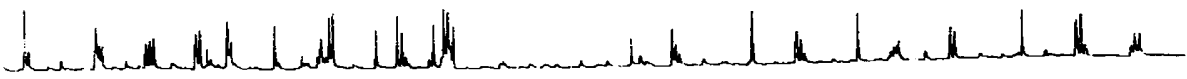

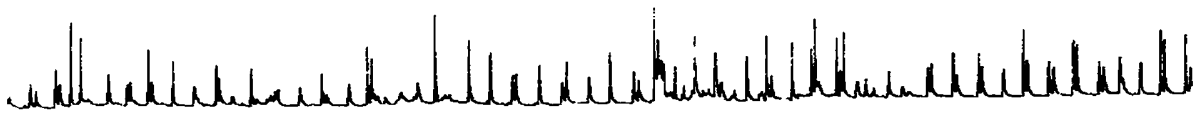
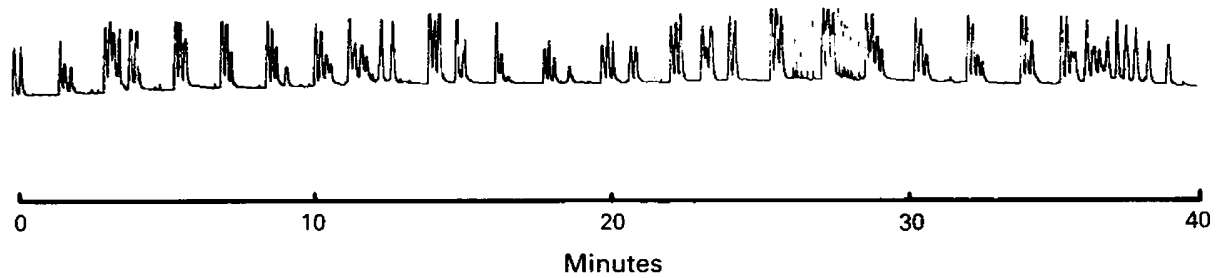

Fig. 1. Intrauterine pressure in an ovariectomized goat before and after administration of $200 \mu \mathrm{g}$ PGI-2 salt.

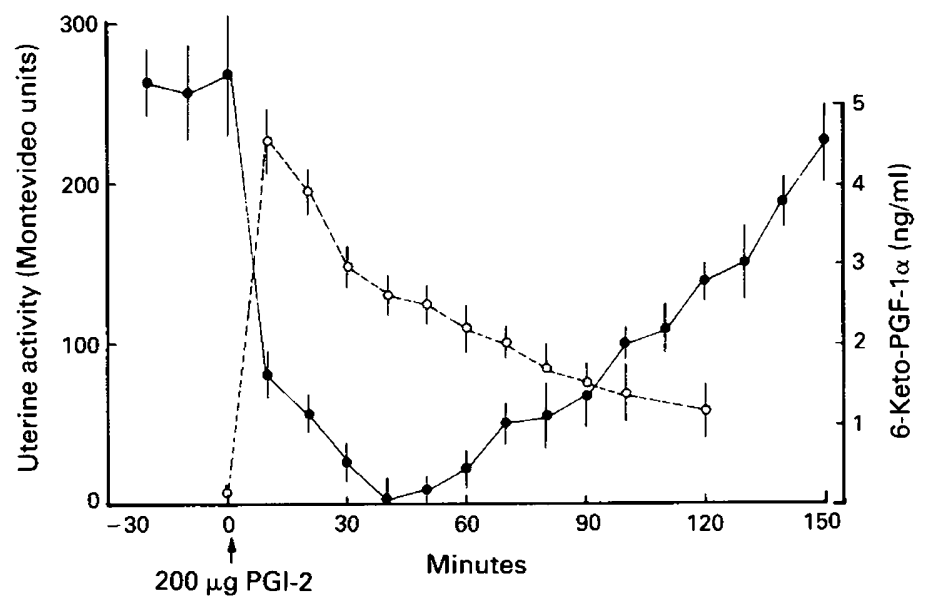

Fig. 2. Mean ( \pm s.e.m.) uterine activity $(\odot)$ and jugular venous plasma concentrations of 6keto-PGF-1 $\alpha(O)$ in 4 ovariectomized goats before and after administration of $200 \mu \mathrm{g}$ PGI-2 salt at time 0 .

6-oxo-PGF-1 $\alpha$, the stable metabolite of PGI-2. Before administration of PGI-2, $1 \mathrm{ml}$ saline had been injected to assess whether the drug vehicle produced any change in uterine motility.

After a period of recovery $(4 \mathrm{~h})$ when uterine activity returned to that observed in the pre-injection phase, doseresponse relationships were determined to doses of oxytocin (Universal Biologicals, Cambridge, UK) and PGF- $2 \alpha$ (Lutalyse: Upjohn Co.); both were suitably diluted in saline so that each was contained in a maximum of $1 \mathrm{ml}$, and were injected into the jugular vein. To minimize possible time-related effects doses of oxytocin and PGF-2 $\alpha$ were administered in random order; each was separated by a 15-min interval. The same sequence of injections was then repeated $20 \mathrm{~min}$ after administration of $200 \mu \mathrm{g}$ PGI-2 as described above. 
Table 1. Mean ( \pm s.e.m.) uterine responses (Montevideo units) in 4 ovariectomized, oestradiol-treated goats to i.v. oxytocin and PGF- $2 \alpha$ before and after treatment with $200 \mu \mathrm{g}$ PGI-2 i.v.

\begin{tabular}{ccrccrr}
\hline \multirow{2}{*}{$\begin{array}{l}\text { Oxytocin } \\
(\mathrm{mU})\end{array}$} & \multicolumn{2}{c}{ Response } & & \multicolumn{2}{c}{ Response } \\
\cline { 2 - 3 } \cline { 5 - 7 } & Before & \multicolumn{1}{c}{ After } & & $(\mu \mathrm{g})$ & \multicolumn{1}{c}{ Before } & \multicolumn{1}{c}{ After } \\
\hline 0 & $290 \pm 26^{*}$ & $28 \pm 8$ & 0 & $276 \pm 25^{*}$ & $25 \cdot 6 \pm 5$ \\
50 & $510 \pm 41$ & $552 \pm 36$ & 1 & $453 \pm 41$ & 418 & \pm 40 \\
100 & $742 \pm 61$ & $726 \pm 51$ & 2 & $663 \pm 45$ & 675 & \pm 45 \\
200 & $879 \pm 71$ & $1051 \pm 80$ & 4 & $1036 \pm 77$ & 1210 & \pm 84 \\
\hline
\end{tabular}

${ }^{*} P<0.001$ compared to corresponding value after treatment.

Uterine responses were expressed in Montevideo units (Caldeyro-Barcia et al., 1957), i.e. the product of mean amplitude and the total number of contractions in a 10 -min period.

Assay of 6-keto-PGI-1a. A specific radioimmunoassay for 6-keto-PGF-1a was used as described by Liggins $e t$ al. (1980), utilizing their antiserum (4V-208) at a dilution of $1: 10000$; 6-keto $\left[5,8,9,11,12,14,15(\mathrm{n})-{ }^{3} \mathrm{H}\right] \mathrm{PGF}-1 \alpha$ (5000 c.p.m./tube) was obtained from Amersham International (Bucks, UK). Standard curves were constructed using pure 6-keto-PGF-l $\alpha$ (Ujpohn). The recovery of added tracer was $77 \pm 15 \%$ (mean \pm s.e.m., $n=9$ ) and results were corrected for extraction losses; the recovery of standards $(20,50,500,1000 \mathrm{pg})$ added to goat plasma was $19 \cdot 1 \pm 1 \cdot 9$, $52.6 \pm 7.8,489 \pm 15.7$ and $893 \pm 22.8 \mathrm{pg}$ (mean \pm s.e.m., $n=6$ ). The non-specific binding was $8 \%$, the sensitivity of the assay $10 \mathrm{pg} /$ tube, and the intra- and inter-coefficients of variation were 6.2 and $12.6 \%$, respectively $(n=12)$. Antiserum specificity has been reported previously (Liggins et al., 1980).

Data analysis. Data were analysed using two-way ANOVA and Duncan's multiple range test, and Student's $t$ test for paired data.

\section{Results}

Injection of $1 \mathrm{ml}$ saline vehicle did not have any effect on uterine motility in the 4 goats. Figure 1 shows a representative trace of the effects of PGI-2 $(200 \mu \mathrm{g})$ on uterine motility in one ovariectomized goat during treatment with oestradiol benzoate. There was a rapid decline in activity within $10 \mathrm{~min}$, with a peak effect after about $30 \mathrm{~min}$. Activity returned slowly and was still significantly $(P<0.01)$ below pre-injection values after $2.0 \mathrm{~h}$. The results for all 4 animals are presented in Fig. 2. Concentrations of 6-keto-PGF-1 $\alpha$ decreased progressively to $50 \%$ of initial values after about $30 \mathrm{~min}$; at the start of the recovery period concentrations were still greater than $2 \mathrm{ng}^{\mathrm{ml}} \mathrm{ml}^{-1}$. Table 1 shows the mean responses to various doses of intravenous oxytoxin and PGF- $2 \alpha$ before and after treatment with $200 \mu \mathrm{g}$ PGI-2. Reactivity to both agents, at all dose levels, was not significantly $(P<0.05)$ affected, i.e the dose-response curves for both oxytocin and PGF-2 $\alpha$ were unaltered by PGI-2, even though spontaneous activity was significantly $(P<0.001)$ reduced.

\section{Discussion}

The results of this study show that PGI-2 inhibits spontaneous uterine motility in the goat; similar results have been reported for the sheep (Lye \& Challis, 1982). Such an acute effect of PGI-2 may be of importance in rendering the uterus quiescent before implantation when progesterone concentrations are very low (Thorburn \& Schneider, 1972; Irving et al., 1972). This is supported by several observations. While PGI-2 is present in the goat corpus luteum, highest concentrations of its metabolites, 6-keto-PGF-2 $\alpha$, have been found in the myometrium and endometrium, and concentrations increase significantly during early pregnancy (Cooke \& Homeida, 1987); in this respect it may be beneficial to compare uterine activity, and responses to PGI-2, in non-pregnant and early pregnant goats. PGI-2 has also been shown to regulate uterine blood flow in the rat (Kennedy \& 
Zamecnik, 1978), to assist blastocyst implantation in women (Kelly, 1981), and be luteotrophic in the cow both in vitro and in vivo (Milvae \& Hansel, 1980).

The prolonged effect of PGI-2 on the goat uterus was surprising considering its short half-life of $3 \mathrm{~min}$ in blood or biological buffers (Dusting et al., 1978). It is possible that 6-keto PGF-2 $\alpha$ is responsible for the inhibitory effect, but the uterus recovered when plasma concentrations of the metabolite were in excess of 2 ng.ml ${ }^{-1}$, and also it has been reported that 6-keto-PGF-2 $\alpha$ has no effect on human myometrial activity in vitro (Omini et al., 1979). However, bearing in mind the possible species differences in uterine responses to PGI-2 referred to above, it would be useful to examine the effects of the metabolite on uterine motility in ruminants.

As observed in ovariectomized ewes (Lye \& Challis, 1982) both oxytocin and PGF-2 $\alpha$ were able to overcome the inhibitory effects of PGI-2, suggesting that prostacyclin has little effect on receptors to these hormones. This contrasts to the action of progesterone which blocks uterine responsiveness to both oxytocin and PGF- $\alpha$ (R. G. Cooke \& A. M. Homeida, unpublished observations), probably by inhibiting receptor formation (McCracken et al., 1984).

We thank Professor G. C. Liggins, Auckland, NZ, for the gift of 6-oxo-PGF-2 $\alpha$ antiserum and the British Council for financial support (A.M.H.).

\section{References}

Caldeyro-Barcia, R., Sica-Blanco, Y., Poseiro, J.J., Gonzales-Panizza, V., Mendez-Bauer, C., Fielitz, C., Alvarez, H., Pose, S.V. \& Hendricks, C.H. (1957) A quantitative study of the action of synthetic oxytocin on the non-pregnant human uterus. J. Pharm. exp. Ther. 121, 18-31.

Cooke, R.G. \& Homeida, A.M. (1987) Alterations in reproductive tissue concentrations of oxytocin and prostaglandins during early pregnancy in the goat. $J$. vet. Med. A34, 415-419.

Dusting, G.L., Moncada, S. \& Vane, J.R. (1978) Disappearance of prostacyclin (PGI $)$ in the circulation of the dog. Br. J. Pharm. 62, 414P.

Irving, G., Jones, D.E. \& Knifton, A. (1972) Progesterone concentration in the plasma of pregnant goats. $J$. Endocr. 53, 447-452.

Jones, D.E. \& Knifton, A. (1975) Effects of female sex hormones on uterine motility and reactivity to oxytocin in goats. Res. vet. Sci. 18, 288-293.

Jones, R.L., Poyser, N.L. \& Wilson, N.H. (1977) Production of 6-oxo-prostaglandin $F_{1 a}$ by rat, guinea-pig and sheep uteri in vitro. Br.J. Pharm. 59, 436P, abstr.

Kelly, R.W. (1981) Prostaglandin synthesis in the male and female reproductive tract. J. Reprod. Fert. 62, 293-304.

Kennedy, T.G. \& Zamecnik, J. (1978) The concentration of 6-keto PGF $_{1 \alpha}$ is markedly elevated at the site of blastocyst implantation in the rat. Prostaglandins 16, 599-605.

Liggins, G.C., Campos, G.A., Roberts, C.M. \& Skinner, S.J. (1980) Production rates of prostaglandin F, 6-keto-PGFI- $\alpha$ and thromboxane $B_{2}$ by perfused human endometrium. Prostaglandins 19, 461-477.

Lye, S.J. \& Challis, J.R.G. (1982) Inhibition by $\mathrm{PGI}_{2}$ of myometrial activity in vivo in non-pregnant ovariectomized sheep. J. Reprod. Fert. 66, 311-315.
McCracken, J.A., Schramm, W. \& Okulicz, W.C. (1984) Hormone receptor control of pulsatile secretion of $\mathrm{PGF}_{2 a}$ from the ovine uterus during luteolysis and its abrogation in early pregnancy. Anim. Reprod. Sci. 7, 57-54.

Milvae, R.A. \& Hansel, W. (1980) The effects of prostacyclin $\left(\mathbf{P G I}_{2}\right)$ and 6-keto-PGF $1 \alpha$ on bovine plasma progesterone and LH concentrations. Prostaglandins 20, 641-647.

Moncada, S., Gryglewski, R., Bunting, S. \& Vane, J.R. (1976) An enzyme isolated from arteries transforms prostaglandin endoperoxides to an unstable substance that inhibits platelet aggregation. Nature, Lond. 263, 663-665.

Omini, C., Folco, G.C., Pasargiklian, R., Fano, M. \& Berri, F. (1979) Prostacyclin (PGI ${ }_{2}$ ) on pregnant human uterus. Prostaglandins 17, 113-120.

Thorburn, G.D. \& Schneider, D.W. (1972) The progesterone concentration in the plasma of the goat during the oestrous cycle and pregnancy. $J$. Endocr. 52, 23-26.

Wikland, M., Lindblom, B., Hammarström, S. \& Wiqvist, N. (1983) The effect of prostaglandin $1_{2}$ on the contractility of the term pregnant human myometrium. Prostaglandins 26, 905-916.

Williams, K.I., Dembenska-Kiec, A., Zmuda, A. \& Gryglewski, R.J. (1978) Prostacyclin formation by myometrial and decidual fractions of the pregnant rat uterus. Prostaglandins 15, 343-350.

Williams, K.I., El Tahir, K.E.H. \& Marcinkiewicz, E. (1979) Dual action of prostacyclin $\left(\mathrm{PGI}_{2}\right)$ on the pregnant rat uterus. Prostaglandins 17, 667-672.

Received 14 December 1988 